\title{
Implementation of Fuel Cell Emulation on DSP and dSPACE Controllers in the Design of Power Electronic Converters
}

\author{
Abraham Gebregergis, Member, IEEE, and Pragasen Pillay, Fellow, IEEE
}

\begin{abstract}
This paper introduces a fuel cell (FC) emulator based on experimentally validated dynamic solid oxide FC (SOFC) and proton exchange membrane FC (PEMFC) models for power electronics converter design and test, and fault diagnosis and mitigation. The FC emulation developed includes both the steady-state and transient responses of an FC. A Matlab/Simulink environment is used to implement the FC model, convert and compile it into a C-program and build into real-time control, which is finally programmed into a dSPACE and/or DSP controller for prototype testing and design and field testing. The output of the controller is sent to a linear power amplifier (power converter) that drives a power converter or a load. Experimental test was carried out to observe the steady-state and transient responses of the FC emulator. Both implementation methods show very good results when compared with the experimental data.
\end{abstract}

Index Terms-Converter, DSP, emulation, fuel cell (FC), simulation.

\section{INTRODUCTION}

$\mathbf{T}$ HE WORLD is facing major challenges in energy demand for a variety of stationary applications including industries, schools, hospitals, houses, etc., as well as in transportation applications, while striving to minimize adverse environmental impacts. Currently, fossil fuels are the most dominant sources of energy in most applications. They have low efficiencies, are unfriendly to the environment, and their source is depleting with time, not to mention foreign-country dependence. Moreover, the trend of increasing energy demand will require the construction of new gasoline engines and fossil-fuel-engine power stations. Alternative energy sources can contribute to the increasing energy demands for stationary applications and transportation applications. Fuel cells (FCs) are an important energy technology for the hydrogen economy and have the potential to revolutionize the way power is generated. They offer cleaner more efficient alternatives to the combustion of

Paper ICPSD-09-42, presented at the 2008 Industry Applications Society Annual Meeting, Edmonton, AB, Canada, October 5-9, and approved for publication in the IEEE TRANSACTIONS ON INDUSTRY APPLICATIONS by the Energy Systems Committee of the IEEE Industry Applications Society. Manuscript submitted for review November 15, 2008 and released for publication June 3, 2009. Current version published January 20, 2010.

A. Gebregergis is with the Innovation Center, Delphi Steering Saginaw, Saginaw, MI 48601 USA (e-mail: abraham.g.gebregergis@delphi.com).

P. Pillay is with the Department of Electrical and Computer Engineering, Concordia University, Montreal, QC H4G 2M1, Canada (e-mail: pillay @encs. concordia.ca).

Color versions of one or more of the figures in this paper are available online at http://ieeexplore.ieee.org.

Digital Object Identifier 10.1109/TIA.2009.2036676 gasoline and other fossil fuels. FCs run on hydrogen, the simplest element and the most plentiful gas in the universe. It has the highest energy content per unit weight of all the fuels $(52000 \mathrm{Btu} / \mathrm{lb}$ or three times the energy of a pound of gasoline). Fuels, like natural gas, methanol, or even gasoline can be reformed to produce the hydrogen required for the FCs.

Most studies have been focusing on modeling, simulation, and optimization of an FC. The FC models are complex and computationally slow, which makes it impossible for real-time emulation [1]-[3]. The use of an actual FC in a prototype design and testing of power electronic converters for interconnecting an FC to a load is expensive, and any failure will damage the FC. Hence, a simple FC model, which is experimentally verified, is used to design an FC emulator. The FC emulator will replace the actual $\mathrm{FC}$ for design and testing. The $\mathrm{FC}$ emulator is cheaper than real FCs, safer for testing products, has a compact design that allows mobility, and with scalable output voltage and power levels.

Some research studies have been done on simulators and emulators for different applications. Solar photovoltaic (PV) and battery emulators can be mentioned as the well-studied emulators [4]-[6]. The $V-I$ curve of a solar PV panel is reproduced by a solar PV emulator [4]. The emulator is used in power electronics design and testing and reduces the overall cost, particularly for high-power solar PV panel. A batteryemulator study was done in [5] and [6]. The emulator replaces the real battery to reduce cost and pollution. Rechargeable batteries were tried but failed to reproduce the same characteristics repeatedly and consistently due to aging. Nonrechargeable batteries were expensive, not to mention that they introduce pollution to the environment.

The demand of FCs for small-scale stationary and transportation applications is greatly increasing, which makes FC emulators important for design, testing, and fault diagnosis. Existing FC simulators and emulators are based on curve fitting, cell equivalent-impedance model, and a real single FC as a reference model [7]-[11]. An FC simulator based on a computer-controlled power rectifier of a proton exchange membrane (PEM) FC (PEMFC) is proposed in [7]. The slow dynamic response of the power rectifier and lack of available FC model parameters are some of the drawbacks. A cubic polynomial function was used to curve fit the steady-state $V-I$ polarization curve of experimentally obtained data from a real FC test [8]. The model is applicable for steady-state response only; it lacks transient response. A related study on a simulator 


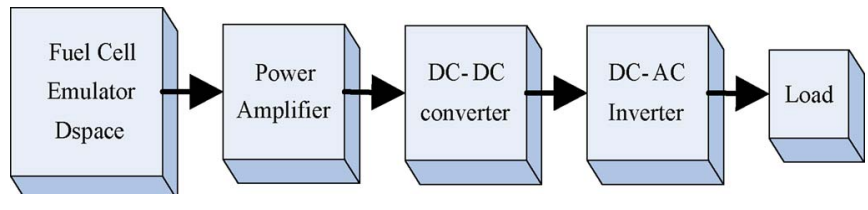

Fig. 1. Block diagram of an FC system and power converter.

is a DSP-based FC simulator using a buck converter, which applies a linear relationship of the output voltage and current of the FC [9]. However, the model considers a linear steadystate response, ignoring the effect of nonlinearity of the FC and lacks dynamic response. Reference [10] proposes a way to include both the transient and steady-state response using an equivalent cell impedance model. The parallel $R C$ circuit in the equivalent-impedance cell replaces the activation and concentration drops of the cell. The Nernst reversible voltage is assumed constant, which is not true in reality. A more comprehensive approach is presented in [11], which uses an actual single $\mathrm{FC}$ as a reference to determine the operating voltage point. This approach is not applicable since the cost of the fuel, the use of the reformer, and preheating equipment increase the cost of the FC system.

This paper presents an FC emulator based on an electrochemical solid oxide FC (SOFC) and PEMFC models. The model takes into account the effects of the Nernst reversible voltage (open-circuit voltage) and the irreversible voltage drop (activation, concentration, and ohmic drops). The model is designed to include both the steady-state and transient responses of the real FC. Fig. 1 shows a block diagram of the FC system, which contains an FC emulator (hardware in the loop) and control, a power converter ( $\mathrm{dc} / \mathrm{dc}$ and/or dc/ac), and a load. The FC emulator and the control are implemented in a Matlab/Simulink environment and programmed into a dSPACE and/or DSP controllers. The control voltage from the FC model is fed into a power amplifier. Finally, the power amplifier drives either a load or a power-converter circuit. The FC emulator is fast, flexible, easily scalable, and can be adapted to other FC types.

\section{FC EMUlator IMPLEMENTATION USING A dSPACE CONTROLLER}

SOFC and PEMFC models are implemented in a Matlab/ Simulink as shown in Fig. 2. Fig. 2 shows the building voltage blocks of the terminal voltage of the FC model. The terminal voltage is given as the summation of four voltage-block models: the Nernst reversible voltage, the activation drop, the concentration drop, and the ohmic drop. This was programmed into the rs1104 R\&D dSPACE real-time controller of Fig. 3 for prototype design and testing. The output voltage from the dSPACE controller is used as a reference control to the linear power amplifier connected to the dc-dc converter (under test) or directly to a load. The dSPACE controller has a 12-b analog-to-digital converter (ADC) for reading the measurement inputs from the sensors, an embedded DSP controller where the FC model and pulsewidth modulation (PWM) controller are loaded, a 12-b digital-to-analog converter to interface the reference cell voltage of the FC model to the power amplifier, and a digital input/output port to send PWM control and receive digital inputs. Fig. 4 shows the dSPACE controller system used to implement the FC model. The implementation of the FC model is presented in five sections based on the FC voltage equation (four voltage model blocks) and the thermal conservation of the cell [1]-[15]

$$
V_{\mathrm{fc}}=E-V_{\mathrm{act}}-V_{\mathrm{con}}-V_{\mathrm{ohmic}}
$$

where $E$ is Nernst reversible voltage, $V_{\text {act }}$ is the activation loss, $V_{\text {con }}$ is the concentration loss, and $V_{\text {ohmic }}$ is the ohmic loss.

\section{A. Nernst Reversible Voltage}

The Nernst reversible voltage of the FC model is given in (2) [1]-[3]. This voltage equation depends on the partial pressure of the individual species, which is determined using the mass flow conservation given in (3) [2]. Equation (4) is the electrical analogy of the electrochemical equation in (3). The electrochemical equation is represented by the parallel $R C$ circuit, as shown in Fig. 5. The voltage measured across the capacitor $C_{i}$ of the parallel $R C$ circuit is equivalent to the partial pressure $P_{i}$ of the gases. The overall output voltage $E_{\text {nernst }}$ of the Simulink model represents the Nernst reversible voltage generated from the $\mathrm{FC}$ model

$$
E=E_{0}+\frac{R T}{2 F} \ln \left(\frac{P_{\mathrm{H}_{2}} \cdot P_{\mathrm{O}_{2}}^{0.5}}{P_{\mathrm{H}_{2} \mathrm{O}}}\right)
$$

where $E_{0}=1.1 \quad \mathrm{~V}$ is the standard potential, $R=$ $8.314 \mathrm{~kJ} / \mathrm{kmol} \cdot \mathrm{K}$ is the universal gas constant, $T$ is the operating temperature of the FC in Kelvin, $F=96486 \mathrm{C} / \mathrm{mol}$ is the Faraday's constant, and $P_{\mathrm{H}_{2}}$ is the hydrogen partial pressure, $P_{\mathrm{H}_{2} \mathrm{O}}$ is the water partial pressure, and $P_{\mathrm{O}_{2}}$ is oxygen partial pressure

$$
\begin{aligned}
\left(\left(\frac{V}{K_{x} R T}\right) s+1\right) P_{x}(s) & =\frac{1}{K_{x}}\left(N_{x}^{\mathrm{in}}-2 n K_{r} I_{\mathrm{fc}}\right) \\
\left(\left(C R_{x}\right) s+1\right) V_{x}(s) & =R_{x}\left(I_{x}^{\mathrm{in}}-2 n K_{r} I_{\mathrm{fc}}\right)
\end{aligned}
$$

where $V$ is the volume of the electrode, $N^{\text {in }}$ is the input mole flow rate, $P_{x}$ is the partial pressure at the exit, $K_{x}$ is the molar valve constant, $C=V / R T$ is the capacitance, $R_{x}=1 / K_{x}$ is the resistance, $K_{r}=N^{r} / 4 F$ is a constant, $I^{\text {in }}$ and $V_{x}$ are the current and voltage equivalent to $N^{\text {in }}$ and $P_{x}$, and $x$ is the individual species.

\section{B. Activation Voltage Drop}

The activation voltage drop is expressed by the ButlerVolmer formula (5) for all cell current values [2]. The Butler-Volmer formula is reduced to (6) if $\alpha_{1}=\alpha_{2}$ for implementation reasons. This voltage drop is dominant at low cellcurrent values only. The Matlab/Simulink implementation of the activation voltage drop $V_{\text {act }}$ is shown in Fig. 6

$$
\begin{aligned}
I_{\mathrm{fc}} & =I_{0}\left(e^{\left(\alpha_{1} F / R T\right) V_{\mathrm{act}}}-e^{\left(-\alpha_{2} F / R T\right) V_{\mathrm{act}}}\right) \\
V_{\mathrm{act}} & =\frac{R T}{n \alpha F} \ln \left(z+\sqrt{z^{2}+1}\right)
\end{aligned}
$$




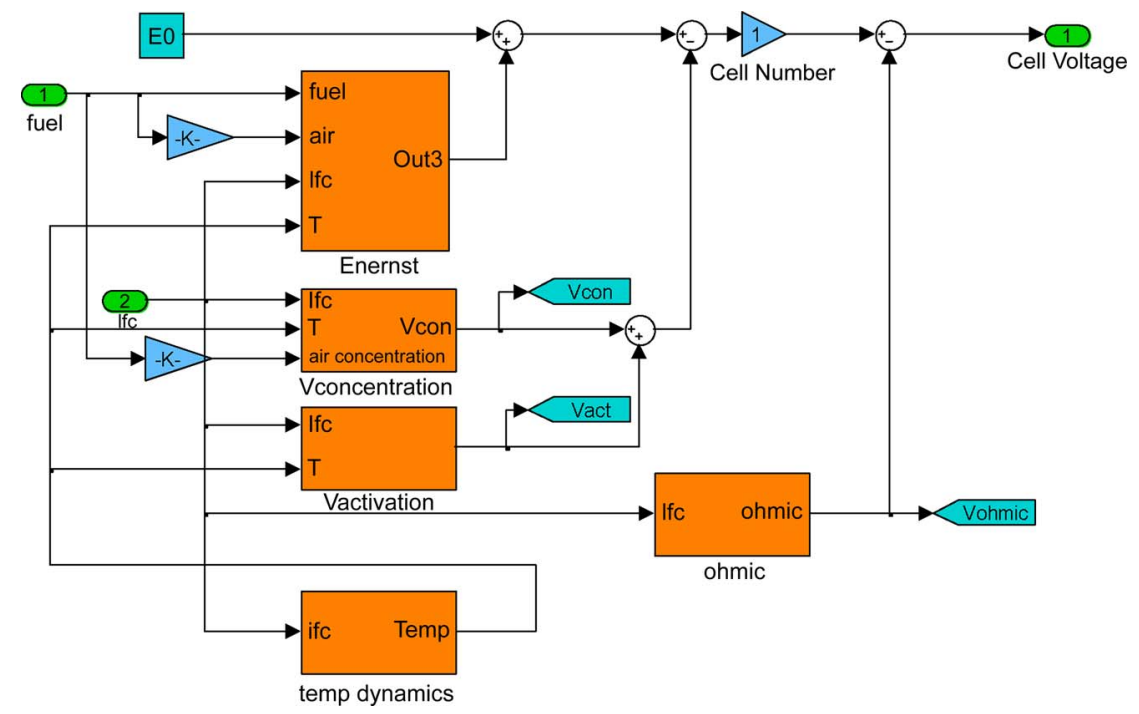

Fig. 2. Simulink model block diagram of the SOFC emulator.

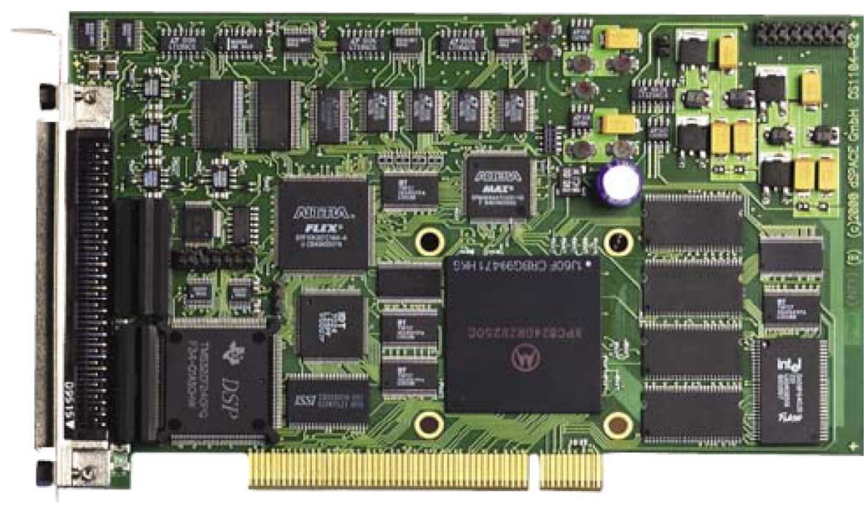

Fig. 3. PCB of the ds1104 R\&D dSPACE controller.

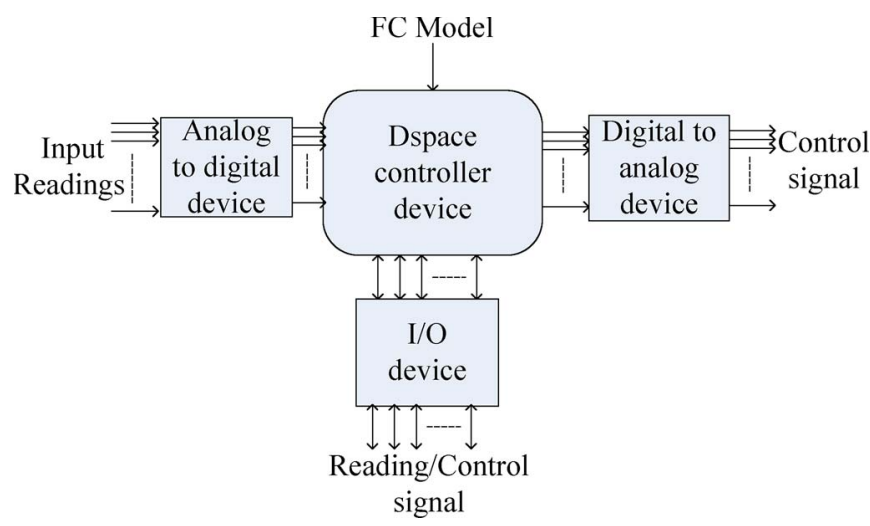

Fig. 4. FC model and PWM dSPACE controller block diagram.

where $z=I_{\mathrm{fc}} / 2 I_{0}$ and $I_{0}$ is the exchange current density of the cell.

\section{Concentration Voltage Drop}

The concentration voltage drop given in (7) is shown in Fig. 7 [2]. This voltage drop is significant when the load current density approaches the limiting current density of the FC. Limiting current density is the maximum possible current density of the cell for a given flow rate. The output $V_{\text {con }}$ in the Simulink model of Fig. 7 represents the concentration drop

$$
V_{\text {con }}=-\frac{R T}{n F} \ln \left(1-\frac{I_{\mathrm{fc}}}{I_{L}}\right)
$$

where $I_{L}$ is the limiting current density of the cell.

\section{Ohmic Voltage Drop}

An equivalent resistor is connected in series to the terminal of the FC model to represent the ohmic voltage drop. The equivalent internal-resistance value of the FC is obtained from the FC manufacturers. However, the resistance of the $\mathrm{FC}$ changes with the operating temperature of the FC, which is given by (8) for SOFC [2], [3] and (9) for PEMFC [14]

$$
\begin{aligned}
r & =\left(\gamma \exp \left[\beta\left(\frac{1}{T_{0}}-\frac{1}{T}\right)\right]\right) \\
r & =0.16-3.54 x 10^{-4} T+8.54 x 10^{-4} I_{\mathrm{fc}} \\
V_{\text {ohmic }} & =r I_{\mathrm{fc}}
\end{aligned}
$$

where $T$ is the FC temperature, $T_{0}=973 \mathrm{~K}, \gamma=0.2$ and $\beta=$ -2870 are constant coefficients of the $\mathrm{FC}$, and $r$ is the total internal resistance of the FC.

\section{E. Thermal Energy Conservation Simulink Model}

The dynamics of the cell temperature given in (11) is represented in Simulink as shown in Fig. 8 [15]. It contains three equation blocks, which determine the heat generated and the heat transfer due to convection and mass diffusion of the species

$$
M_{p} C_{p} \frac{d T}{d t}=q_{e}+\sum q_{t}
$$

where $M_{p}$ is mass of the cell (kilograms), $C_{p}$ is heat capacity of the cell (joules per kilogram-kelvin), $T$ is the cell temperature (kelvin), $q_{e}$ is the rate of heat generated (joules per second) from the electrochemical reaction, and $q_{i}$ is the rate of heat transfer (joules per second), which is the summation of conduction, 


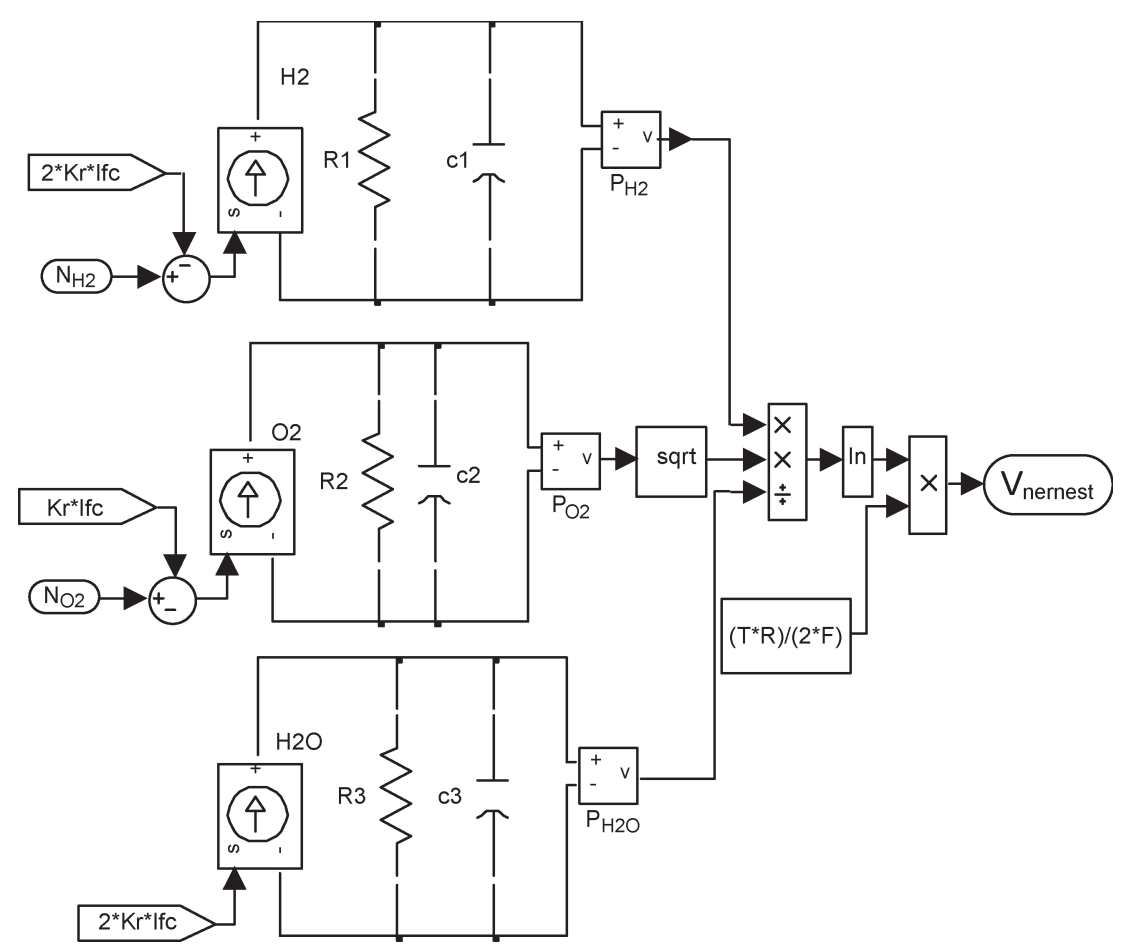

Fig. 5. Nernst reversible voltage in Simulink.

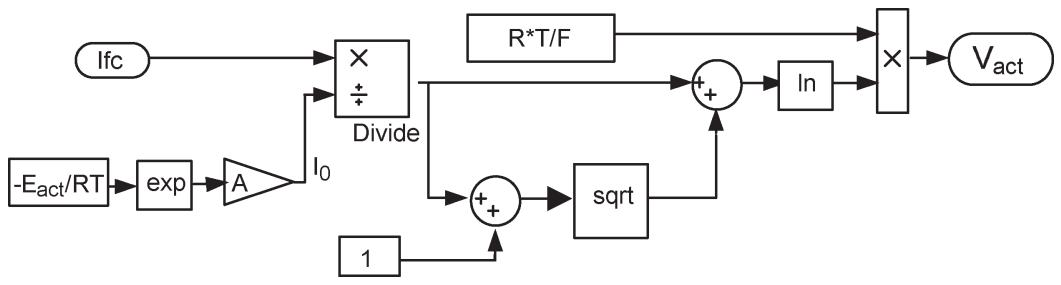

Fig. 6. Activation voltage-drop model using Matlab Simulink.

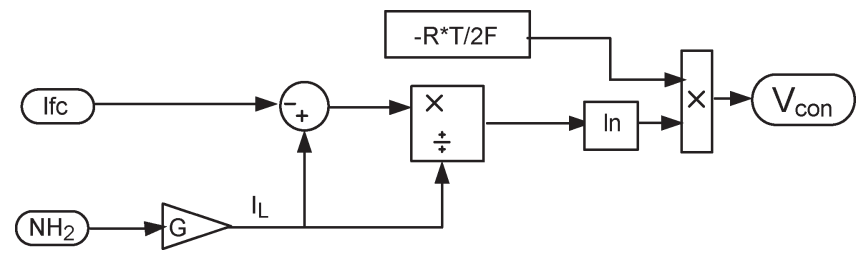

Fig. 7. Concentration voltage-drop model using Matlab Simulink.
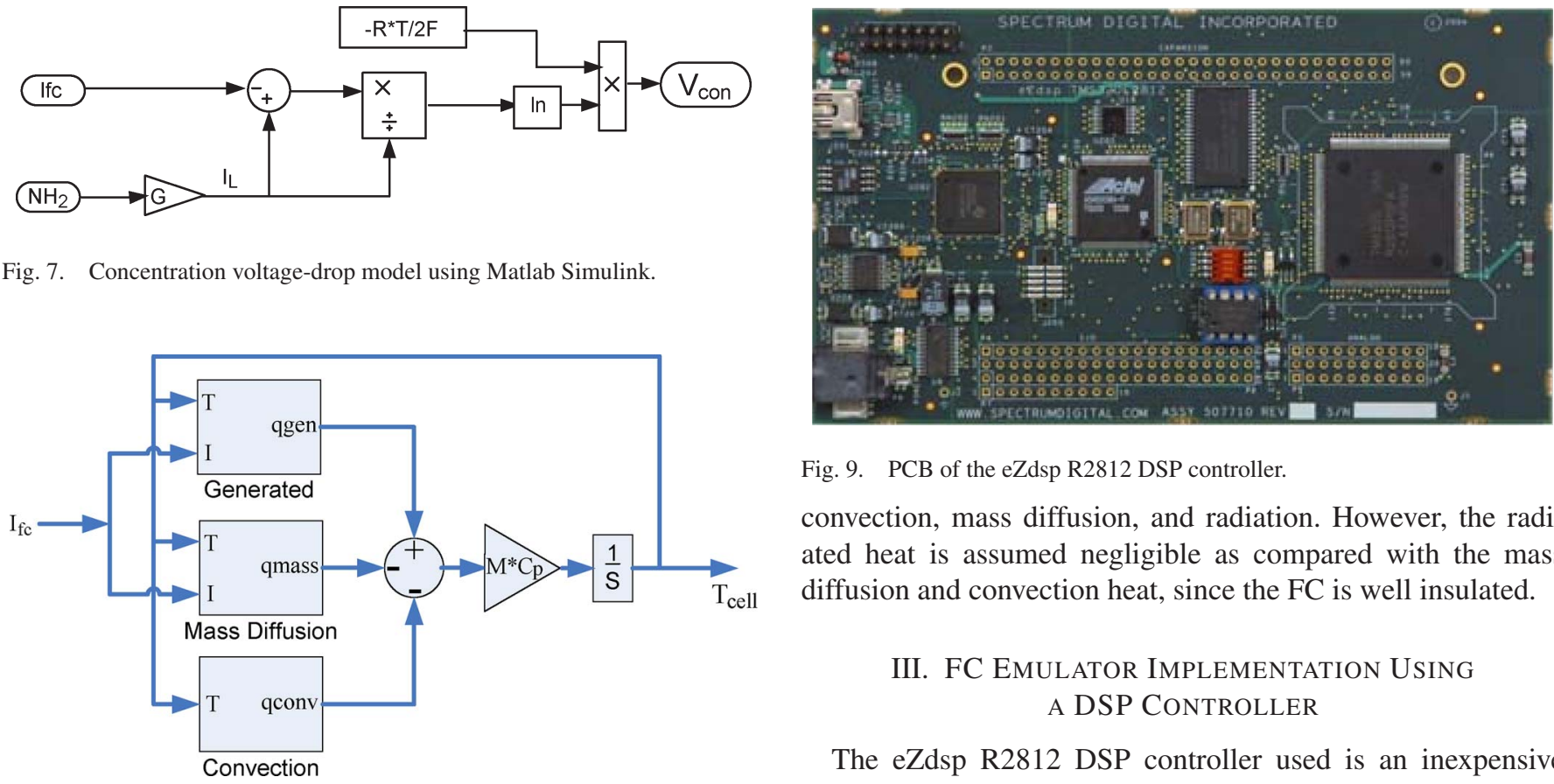

Fig. 9. PCB of the eZdsp R2812 DSP controller.

convection, mass diffusion, and radiation. However, the radiated heat is assumed negligible as compared with the mass diffusion and convection heat, since the FC is well insulated.

\section{FC EMULATOR IMPLEMENTATION USING A DSP CONTROLLER}

The eZdsp R2812 DSP controller used is an inexpensive stand-alone digital controller, which contains an ADC, a dig-

Fig. 8. Thermal energy conservation in Simulink. ital input/output, and TMS320R2812 floating-point DSP. This 


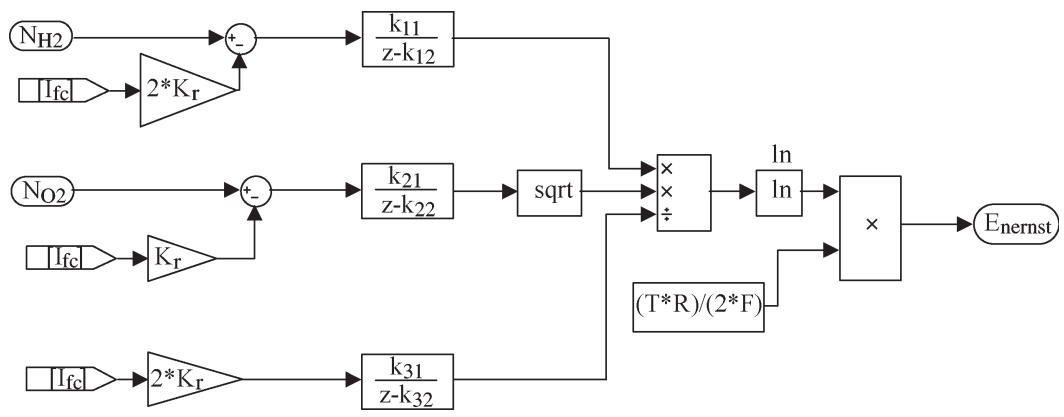

Fig. 10. Flow-rate mass-conservation equation using discrete transfer function.

device requires a Code Composer Studio (CCS) 3.1 and Matlab/ Simulink 2006a to operate properly. The FC model is implemented in Simulink and converted into a C program. The converted program is then built using the CCS, which is eventually loaded into the DSP controller. Fig. 9 shows the actual eZdsp R2812 DSP printed circuit board (PCB) used for the model implementation.

\section{A. Nernst Reversible Voltage}

The continuous-time equivalent $R C$ circuit of the partial pressure of the species is converted into a discrete time transfer functions in order to be implemented in the DSP controller. The Nernst reversible voltage of the FC model for DSP implementation is shown in Fig. 10.

\section{B. Activation, Concentration, and Ohmic Voltage Drops}

Implementation of the irreversible voltages of the FC model are similar for both the dSPACE and the DSP controller. These voltage drops are expressions that can be represented using constant block sets and mathematical expressions. Therefore, the same implementation of the voltage drops used in the dSPACE controller are applied to the DSP-controller-based implementation.

\section{EXPERIMENTAL AND FC EMULATOR RESUlts}

\section{A. FC Emulator Test Setup}

Figs. 11 and 12 show the flowchart and overall experimental test setup of the FC emulator, dSPACE and/or DSP controller and measurements, and the power converter and the load. First, the FC model is built in Simulink for real-time control. The FC model is converted into a C-program using Matlab/Simulink. The C-program is compiled and built to either dSPACE compatible or DSP compatible. Finally, a dSPACE software is used to build the dSPACE-compatible real-time program and is loaded into the rs1104 R\&D dSPACE controller. Similarly, CCS 3.1 is used to build the DSP-compatible program and is loaded into the eZdsp R2818 DSP controller, as shown in Fig. 12. Moreover, the dSPACE and/or DSP controller were used to generate the PWM switching control of the dc-dc power converter and the dc/ac inverter. A 5-kW LCV5050 linear power-supply amplifier with a slew rate of $30 \mathrm{~V} / \mu$ s was used to interface the FC model to the power converter or the load during the test, as shown in Fig. 12.

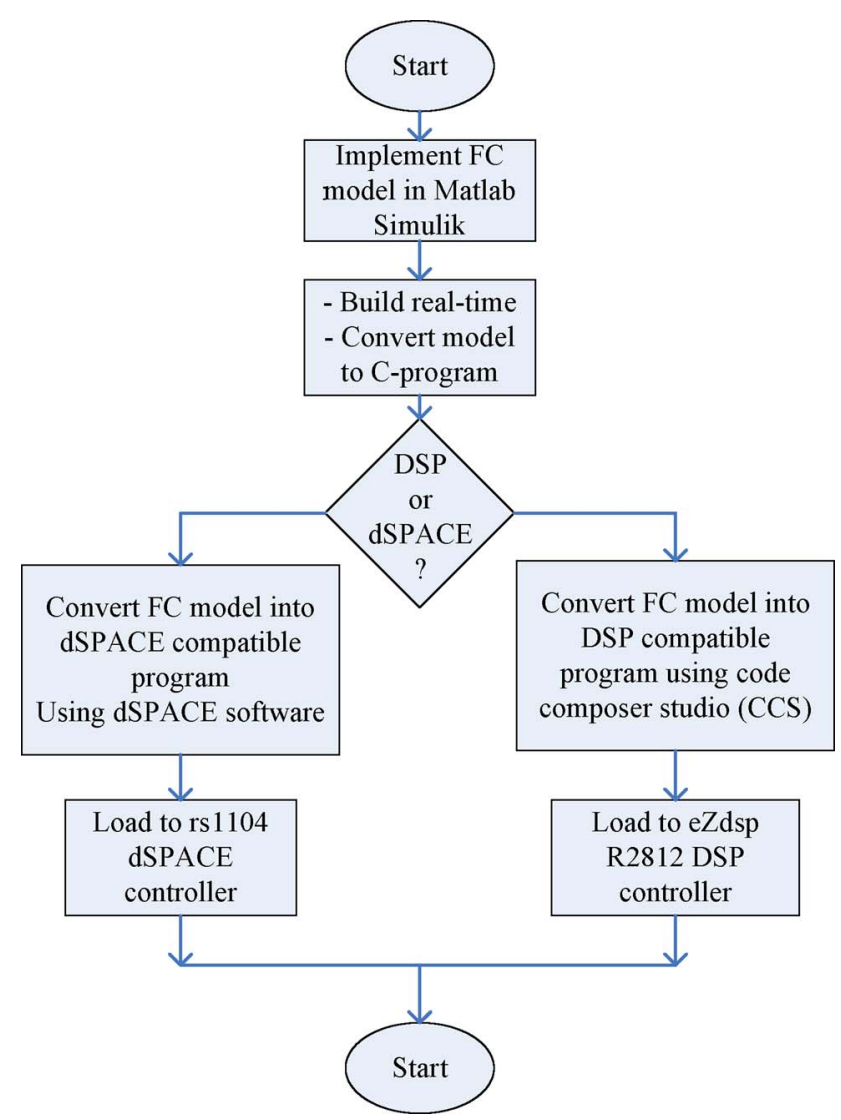

Fig. 11. Flowchart of the loading procedure.

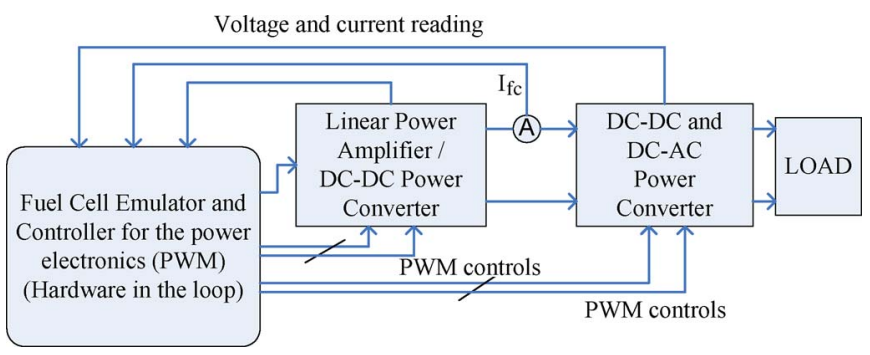

Fig. 12. Overall experimental setup of the FC emulator.

\section{B. SOFC Emulator Results}

1) Steady-State Response: The signal terminal of the linear power amplifier is connected to the FC emulator reference, and the output power of the power amplifier drives a variable resistive load to obtain the static response. $V-I$ polarization curves 


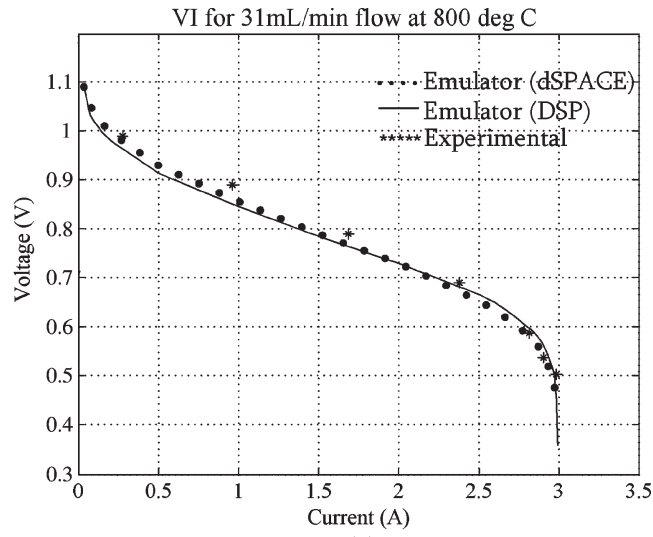

(a)

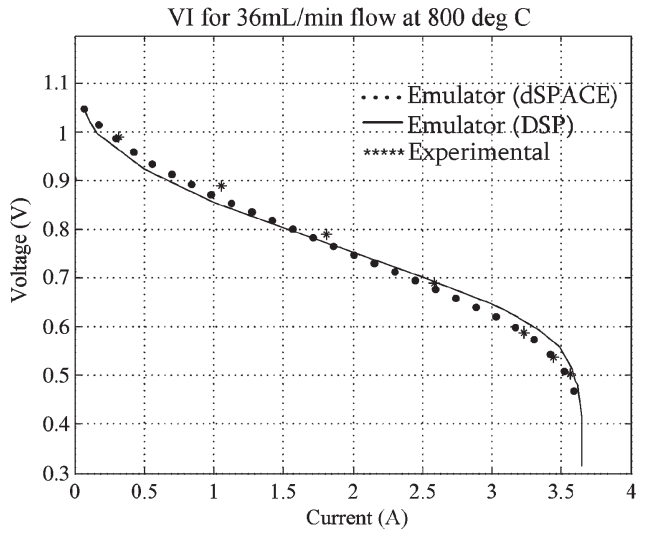

(b)

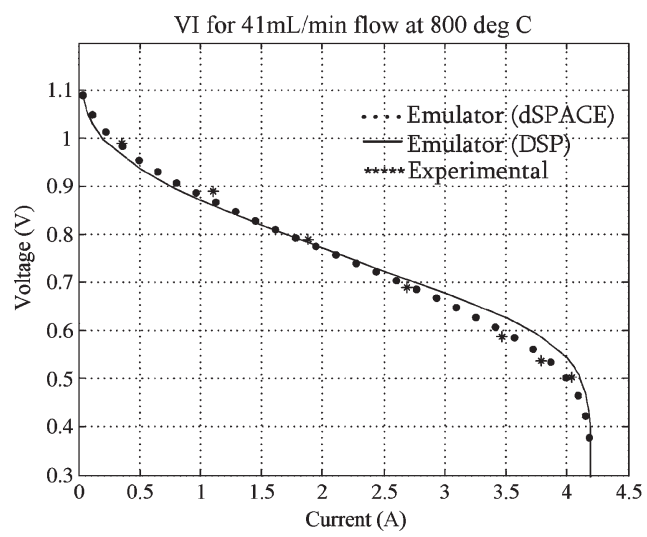

(c)

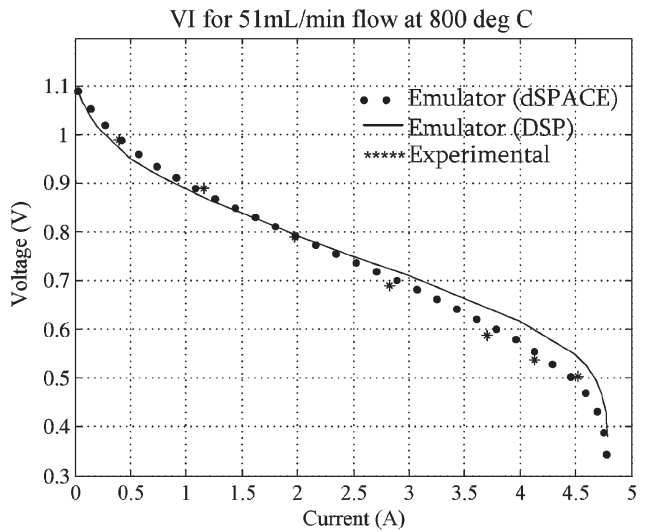

(d)

Fig. 13. $V-I$ polarization curves at $800{ }^{\circ} \mathrm{C}$ operating temperature and four flow rates. (a) $V-I$ curves at $31 \mathrm{~mL} / \mathrm{min}$. (b) $V-I$ curves at $36 \mathrm{~mL} / \mathrm{min}$. (c) $V-I$ curves at $41 \mathrm{~mL} / \mathrm{min}$. (d) $V-I$ curves at $51 \mathrm{~mL} / \mathrm{min}$.

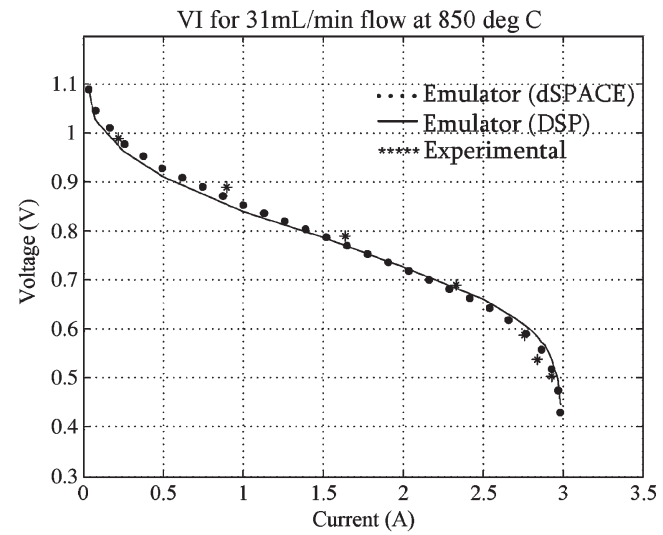

(a)

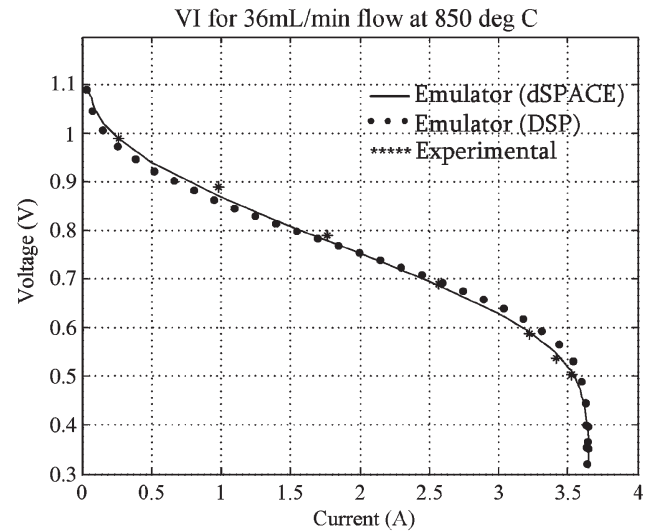

(b)

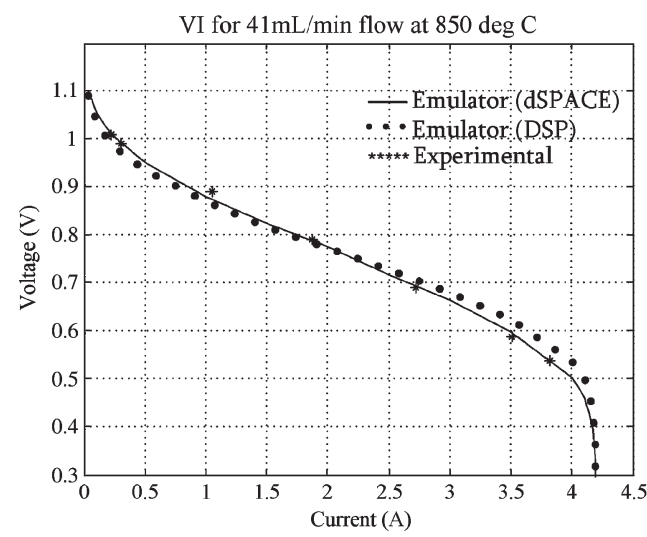

(c)

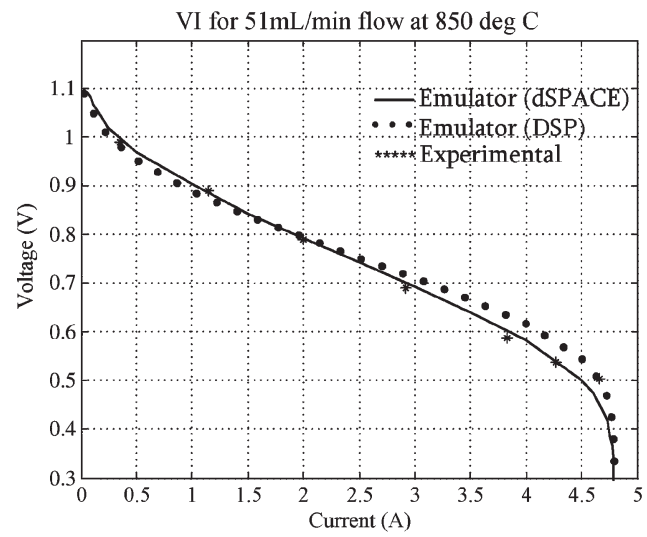

(d)

Fig. 14. $V-I$ polarization curves at $850{ }^{\circ} \mathrm{C}$ operating temperature and four flow rates. (a) $V-I$ curves at $31 \mathrm{~mL} / \mathrm{min}$. (b) $V-I$ curves at $36 \mathrm{~mL} / \mathrm{min}$. (c) $V-I$ curves at $41 \mathrm{~mL} / \mathrm{min}$. (d) $V-I$ curves at $51 \mathrm{~mL} / \mathrm{min}$. 


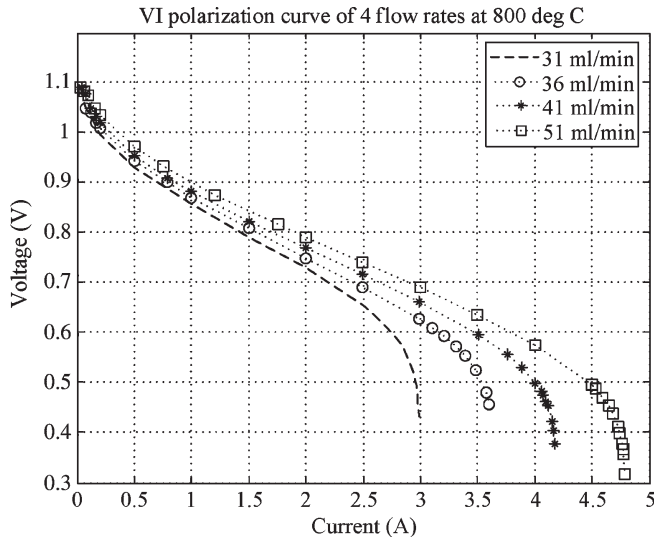

(a)

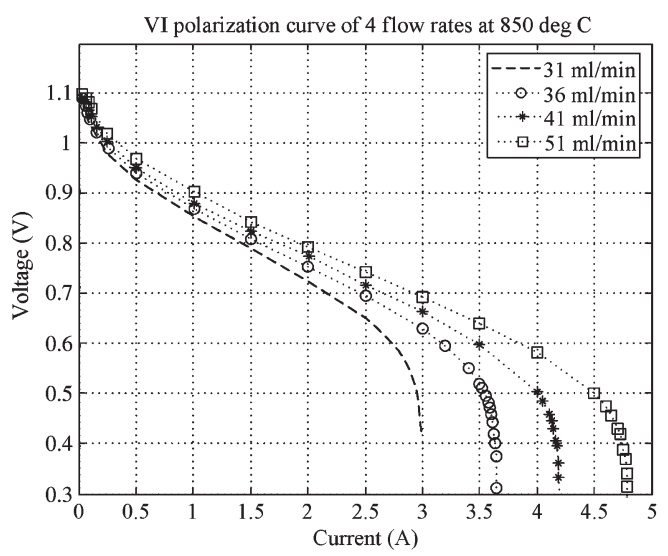

(b)

Fig. 15. Comparison between $V-I$ curves of the four flow rates. (a) $V-I$ curves at $800^{\circ} \mathrm{C}$. (b) $V-I$ curves at $850^{\circ} \mathrm{C}$.

of different flow rates and cell temperatures were obtained. Four flow-rate values $(31,36,41$, and $51 \mathrm{~mL} / \mathrm{min})$ and two cell temperatures $\left(800^{\circ} \mathrm{C}\right.$ and $850{ }^{\circ} \mathrm{C}$ ) were selected to characterize the steady-state response. The $V-I$ curve comparison between the dSPACE, DSP, and experimental data at $800{ }^{\circ} \mathrm{C}$ and $850{ }^{\circ} \mathrm{C}$ are shown in Figs. 13 and 14, respectively, for the four flow rates. The $V-I$ curves show that the FC emulators behave to a high degree as a real FC during the steady state. Although further adjustment on the parameters used can enhance the results of the FC emulator, the existing emulator is good enough to replace the real FC for testing, design, and fault diagnosis.

Fig. 15 shows the $V-I$ curves of the four flow rates in a single graph at $800{ }^{\circ} \mathrm{C}$ and $850{ }^{\circ} \mathrm{C}$ cell temperatures. At both cell temperatures $\left(800{ }^{\circ} \mathrm{C}\right.$ and $850{ }^{\circ} \mathrm{C}$ ), the profile of the $V-I$ curves are similar, with higher cell voltage at $850{ }^{\circ} \mathrm{C}$ than at $800{ }^{\circ} \mathrm{C}$. At low cell current (activation region), the four flow rates almost overlap. As the cell current increases (toward the ohmic and concentration region), the $V-I$ curve with the lower flow rate starts to drop faster, as shown in Fig. 15. The limiting current density of the cell changes as a function of the input flow. The corresponding limiting current for the highest flow rate $(51 \mathrm{~mL} / \mathrm{min})$ is about $4.78 \mathrm{~A}$, and is about $3 \mathrm{~A}$ for the lowest flow rate $(31 \mathrm{~mL} / \mathrm{min})$. This limiting current controls the $V-I$ curve at high cell current around the concentration region. The $V-I$ curve at $31 \mathrm{~mL} / \mathrm{min}$ falls to zero voltage at about $3-\mathrm{A}$ cell current, while the maximum cell current for the $51 \mathrm{~mL} / \mathrm{min}$ flow rate is about $4.78 \mathrm{~A}$.
2) Dynamic Response: The dynamic response of the FC emulator (dSPACE controller) presented here is obtained for a change applied in the flow rate and cell voltage, keeping all the other variables constant. An increase from 35 to $50 \mathrm{~mL} / \mathrm{min}$ in a step of $5 \mathrm{~mL} / \mathrm{min}$ and a decrease from 50 to $35 \mathrm{~mL} / \mathrm{min}$ in a step of negative $5 \mathrm{~mL} / \mathrm{min}$ of the flow rate, maintaining the cell voltage constant, were applied. The cell-current transient response obtained is shown in Fig. 16. Fig. 16(a)-(c) shows the current-response comparison between experimental data and FC emulator results for an increase in the flow rate at constant cell voltage of $0.65 \mathrm{~V}$ and $850{ }^{\circ} \mathrm{C}$. The current transient for a decrease in the flow rate is also shown in Fig. 16(d)-(f). Increasing the flow rate forces the cell current to increase with a first-degree order response. Similarly, a step decrease of the flow rate decreases the cell current of the FC. These responses are the reflection of the equivalent electrical circuit of the flowrate conservation. The results have the same time constant regardless of the amount of change applied in the flow rate.

The transient response of the cell current obtained for the applied change in the cell voltage at constant flow rate of $45 \mathrm{~mL} / \mathrm{min}$ and operating temperature of $800{ }^{\circ} \mathrm{C}$ is shown in Fig. 17. An electronic load model incorporated inside the FC emulator model is used to achieve the required change in the cell voltage. The electronic-load (model) controller is designed to operate at the linear region $(700$ to $800 \mathrm{mV})$ of the $V-I$ curve of the cell. Fig. 17(a)-(d) shows the cell-current dynamics of the FC emulator and the experimental data for a decrease in the cell voltage applied. The cell-current transient obtained for an increase in the cell voltage applied are shown in Fig. 17(e) and (f). The cell-current transients shown in Fig. 17(a) and (f) do not follow exactly the experimental data since the step change in the cell voltage is applied around the nonlinear region (activation and concentration region) of the $V-I$ curve of the FC (about $150 \mathrm{mV}$ apart from intent of the designed electronicload controller) and the assumption that the limiting current is not affected by a change in gas diffusion. The remaining current transient responses shown in Fig. 17(b)-(e) are in fairly good agreement with the experimental data. The reason is that the cell-voltage change is applied around the linear region (ohmic region 700 to $800 \mathrm{mV}$ ) of the $V-I$ curve, which the electronicload model can be modified to respond well for the nonlinear region. In almost all applications, the FCs are operated in the linear region where maximum power output is obtained.

\section{PEMFC Emulator Results}

Similar procedures that were used to perform the SOFC emulator test is applied to the PEMFC emulator. The results discussed are in regard to PEMFC emulator implemented in the DSP controller. The PEMFC model is compiled in Matlab/ Simulink to generate $\mathrm{C}$-program. The $\mathrm{C}$ program is then run in CCS. The CCS builds the make, hex, and out file, which are loaded into the DSP controller. Steady-state results of the PEMFC emulator are shown in Fig. 18. Three flow rates are preselected to show the comparison between the PEMFC model (lumped and distributed models), PEMFC emulator, and the experimental data. The $V-I$ curves at $1,1.5$, and $2 \mathrm{~L} / \mathrm{min}$ are shown in Fig. 18. The results of the PEMFC model and the 


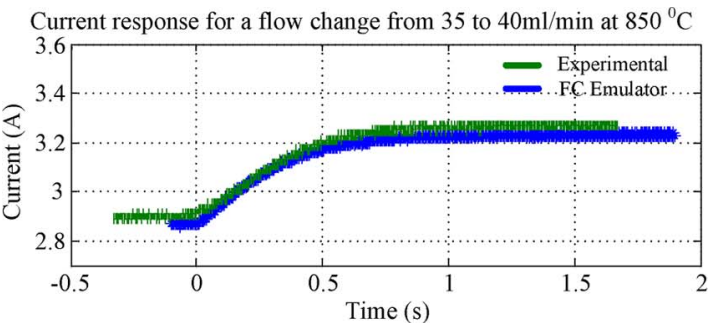

(a)

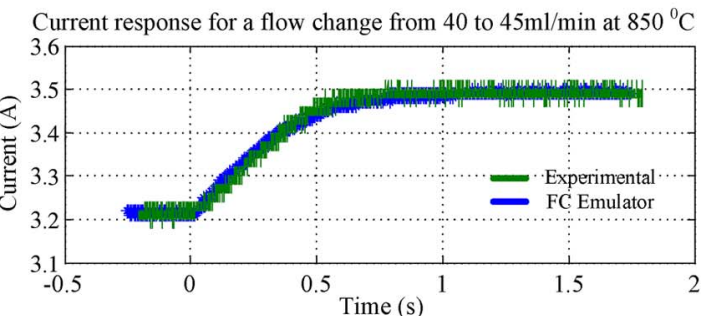

(b)

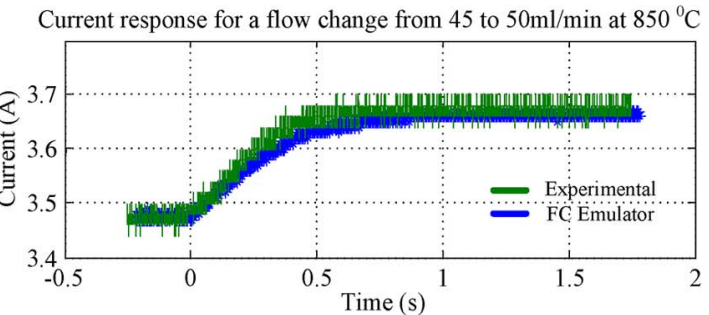

(c)

Current response for a flow change from 40 to $35 \mathrm{ml} / \mathrm{min}$ at $850{ }^{\circ} \mathrm{C}$

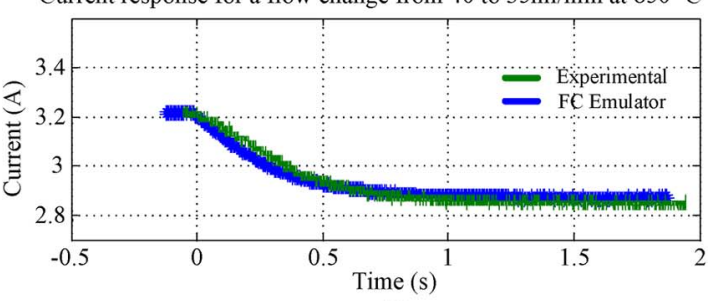

(d)

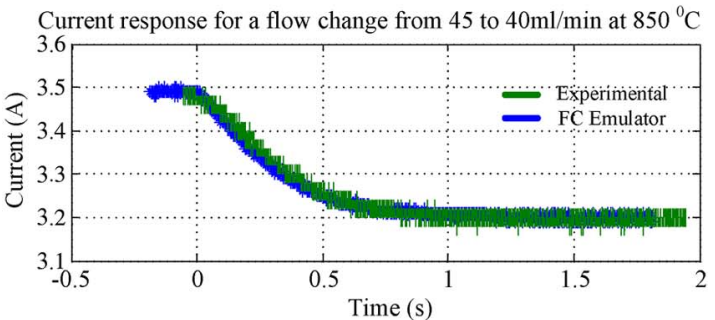

(e)

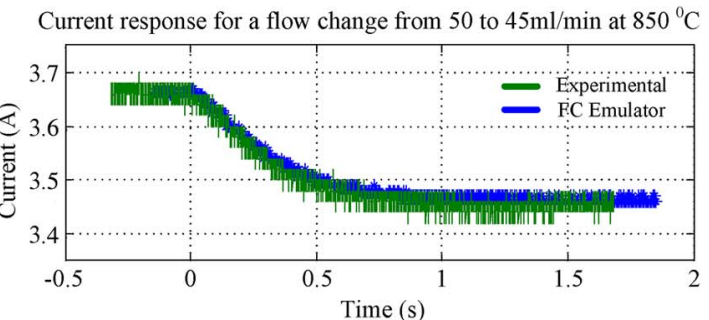

(f)

Fig. 16. Cell current response for a decrease in the flow rate at constant cell voltage of $0.65 \mathrm{~V}$ and $850^{\circ} \mathrm{C}$ operating temperature. (a) Response for a flow change from 35 to $40 \mathrm{~mL} / \mathrm{min}$. (b) Response for a flow change from 40 to $45 \mathrm{~mL} / \mathrm{min}$. (c) Response for a flow change from 45 to $50 \mathrm{~mL} / \mathrm{min}$. (d) Response for a flow change from 40 to $35 \mathrm{~mL} / \mathrm{min}$. (e) Response for a flow change from 45 to $40 \mathrm{~mL} / \mathrm{min}$. (f) Response for a flow change from 50 to $45 \mathrm{~mL} / \mathrm{min}$.

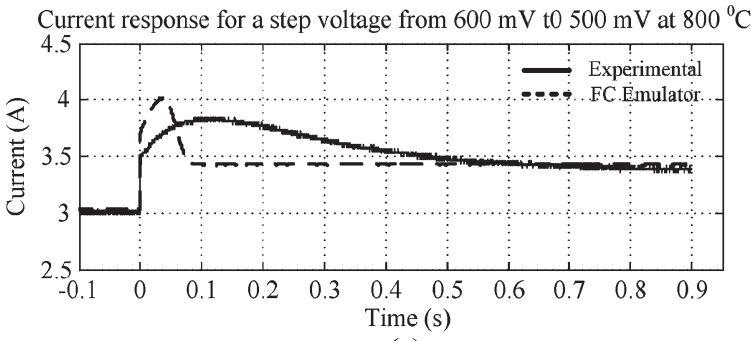

(a)

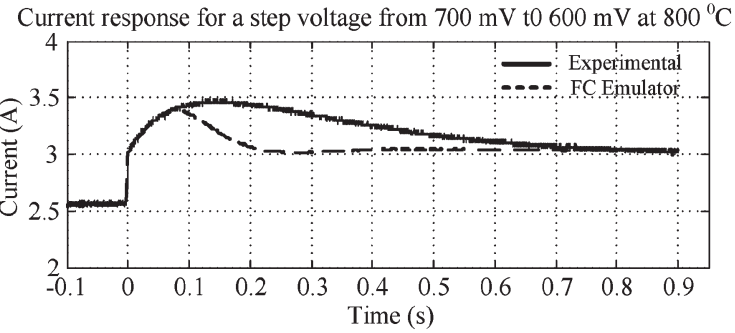

(b)

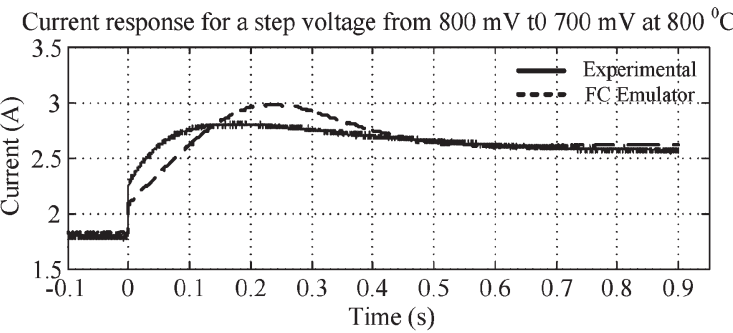

(c)

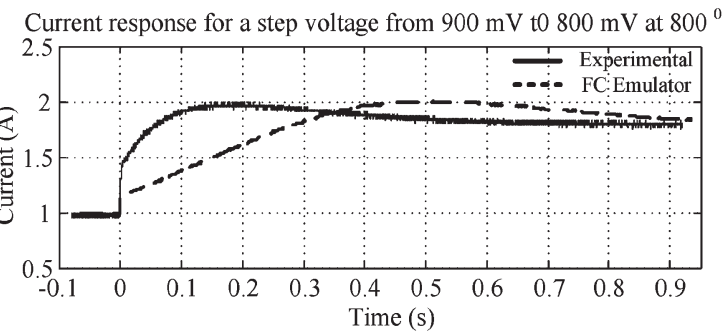

(d)

Current response for a step voltage from $600 \mathrm{mV} \mathrm{t0} 700 \mathrm{mV}$ at $800{ }^{\circ} \mathrm{C}$

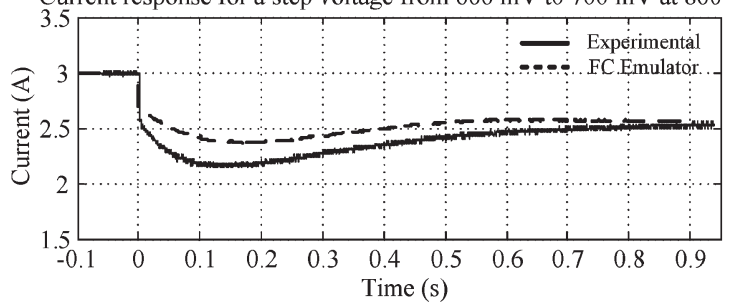

(e)

Current response for a step voltage from $700 \mathrm{mV}$ t0 $900 \mathrm{mV}$ at $800{ }^{\circ} \mathrm{C}$

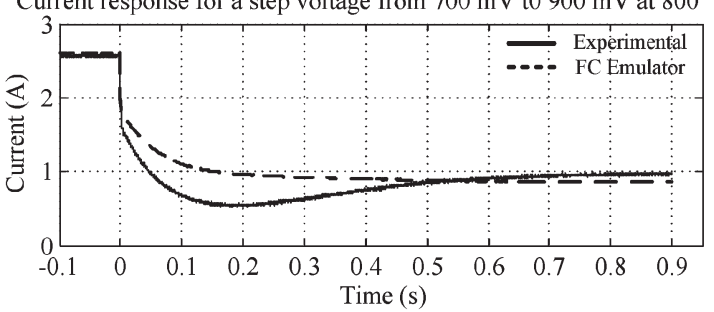

(f)

Fig. 17. Dynamic response of the cell current for a step change in the cell voltage at constant flow rate of $45 \mathrm{~mL} / \mathrm{min}$ and temperature of $800{ }^{\circ} \mathrm{C}$. (a) Response for voltage change from 0.6 to $0.5 \mathrm{~V}$. (b) Response for voltage change from 0.7 to $0.6 \mathrm{~V}$. (c) Response for voltage change from 0.8 to $0.7 \mathrm{~V}$. (d) Response for voltage change from 0.9 to $0.8 \mathrm{~V}$. (e) Response for voltage change from 0.6 to $0.7 \mathrm{~V}$. (f) Response for voltage change from 0.7 to $0.9 \mathrm{~V}$. 


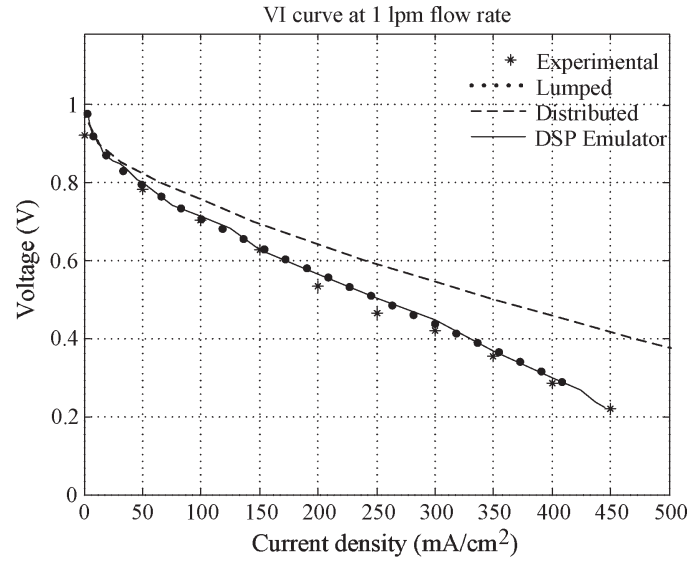

(a)

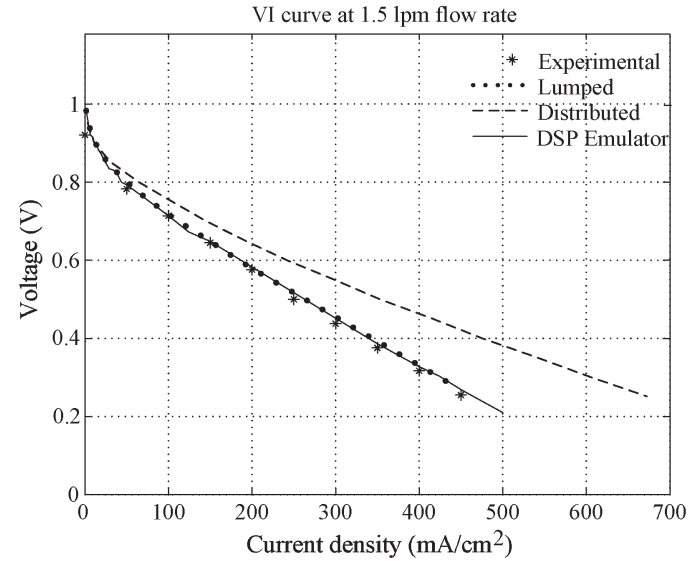

(b)

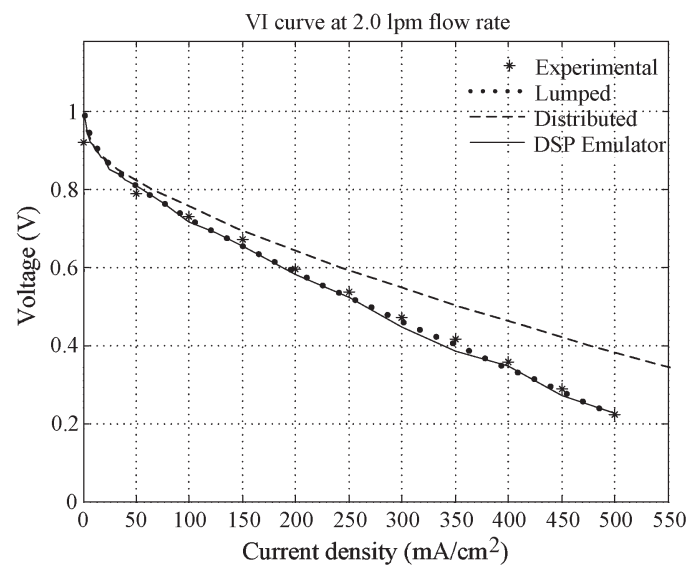

(c)

Fig. 18. $\quad V-I$ polarization curves of a PEMFC at $60^{\circ} \mathrm{C}$ operating temperature and three flow rates. (a) $V-I$ curves at $1.0 \mathrm{~L} / \mathrm{min}$. (b) $V-I$ curve at $1.5 \mathrm{~L} / \mathrm{min}$. (c) $V-I$ curves at $2 \mathrm{~L} / \mathrm{min}$.

emulator have a high degree of correlation with the experimental data. The results of the distributed model deviation increases at high cell current, since the limiting current of the model is calculated while the lumped model uses measured limiting cell current.

\section{CONCLUSION}

An inexpensive fast simple FC emulator that is important for testing purposes and other related applications was pre- sented. The SOFC and PEMFC emulators were implemented in dSPACE and DSP controllers. The dSPACE control is applicable for prototype testing and design, and the DSP control is suitable for field testing. Both static and dynamic responses were compared with experimental data to validate the proposed FC emulators.

\section{REFERENCES}

[1] D. J. Hall and R. G. Colclaser, "Transient modeling and simulation of a tubular solid oxide fuel cell," IEEE Trans. Energy Convers., vol. 14, no. 3, pp. 749-753, Sep. 1999.

[2] D. Bhattacharyya, R. Rengaswamy, and F. Caine, "Isothermal models for anode-supported tubular solid oxide fuel cells," Chem. Eng. Sci., vol. 62, no. 16, pp. 4250-4267, 2007. DOI:10.1016/j.ces.2007.04.020.

[3] Y. Qi, B. Huang, and K. T. Chuang, "Dynamic modeling of SOFC: The effect of diffusion and inherent impedance," J. Power Sources, vol. 150, pp. 32-47, Oct. 2005.

[4] C. Yew, T. Jia, J. Au, and W. Kong, "An embedded microchip system design for programmable solar panel simulator," in Proc. PEDS, Nov. 28-Dec. 1, 2005, vol. 2, pp. 1606-1610.

[5] P. H. Chou, C. Park, J. Park, K. Pham, and J. Liu, "\#B: A battery emulator and power-profiling instrument," in Proc. ISLPED, Aug. 25-27, 2003, pp. $288-293$.

[6] C. Park, J. Liu, and P. H. Chou, “\#B: A battery emulator and powerprofiling instrument," IEEE Des. Test Comput., vol. 22, no. 2, pp. 150159, Mar./Apr. 2005.

[7] J. M. Correa, F. A. Farret, J. R. Gomes, and M. G. Simoes, "Simulation of fuel-cell stacks using a computer-controlled power rectifier with the purposes of actual high-power injection applications," IEEE Trans. Ind. Appl., vol. 39, no. 4, pp. 1136-1142, Jul./Aug. 2003.

[8] P. Acharya, P. Enjeti, and I. J. Pitel, "An advanced fuel cell simulator," in Proc. IEEE APEC, Anaheim, CA, Feb. 22-26, 2004, pp. 1554-1558.

[9] T.-W. Lee, S.-H. Kim, Y.-H. Yoon, S.-J. Jang, and C.-Y. Won, "A 3-kW fuel cell generation system using the fuel cell simulator," in Proc. IEEE Int. Symp. Ind. Electron., May 4-7, 2004, vol. 2, pp. 833-837.

[10] M. Ordonez, M. T. Iqbal, and J. E. Quaicoe, "Development of a fuel cell simulator based on an experimentally derived model," in Proc. IEEE CCECE, Saskatoon, SK, Canada, May 1-4, 2005, pp. 1449-1452.

[11] M. Ordonez, M. T. Iqbal, and J. E. Quaicoe, "A novel fuel cell simulator," in Proc. IEEE 36th Power Electron. Spec. Conf., Jun. 12, 2005, pp. $178-184$.

[12] J. Larminie and A. Dicks, Fuel Cells Systems Explained, 2nd ed. Hoboken, NJ: Wiley, 2003.

[13] R. O'Hayre, S.-W. Cha, W. Colella, and F. B. Prinz, Fuel Cell Fundamentals. Hoboken, NJ: Wiley, 2006.

[14] J. C. Amphlett, R. M. Baumert, R. F. Mann, B. A. Peppley, and P. R. Roberge, "Performance modeling of the Ballard Mark IV solid polymer electrolyte fuel cell. I. Mechanistic model development," J. Electrochem. Soc., vol. 142, no. 1, pp. 1-8, Jan. 1995.

[15] X. Xue, J. Tang, N. Sammes, and Y. Du, "Dynamic modeling of single tubular SOFC combining heat/mass transfer and electrochemical reaction effects," J. Power Sources, vol. 142, no. 1/2, pp. 211-222, Mar. 2005.

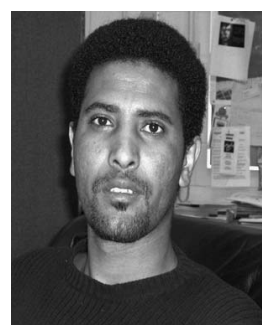

Abraham Gebregergis (S'07-M'08) received the B.S. degree from Asmara University, Asmara, Eritrea, in 2001, the M.S. degree from Stellenbosch University, Stellenbosch, South Africa, in 2004, and the Ph.D. degree from Clarkson University, Potsdam, NY.

He is currently with Delphi Steering Saginaw, Saginaw, MI, as a Project Engineer. His research interests include power electronics, drives and machines, electric power steering, control, and fuel cell modeling. 


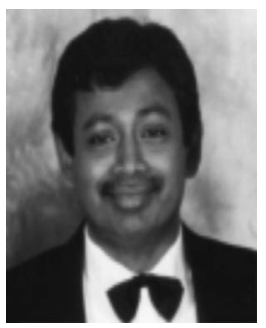

Pragasen Pillay (S'84-M'87-SM'92-F'05) received the B.S. and M.S. degrees from the University of KwaZulu-Natal, Durban, South Africa, in 1981 and 1983, respectively, and the Ph.D. degree from Virginia Polytechnic Institute and State University, Blacksburg, in 1987, while funded by a Fulbright Scholarship.

From January 1988 to August 1990, he was with the University of Newcastle upon Tyne, Newcastle upon Tyne, U.K. From August 1990 to August 1995, he was with the University of New Orleans, New Orleans, LA. From 1996 to December 2007, he was with Clarkson University, Potsdam, NY. He is currently with Concordia University, Montreal, QC, Canada, where he is a Professor and Hydro-Quebec Senior Chair in the Department of Electrical and Computer Engineering and holds the Jean Newell Distinguished Professorship in Engineering. He has also been an Adjunct Professor at the University of Cape Town, Cape Town, South Africa, since 1999. His research and teaching interests are in modeling, design, and control of electric motors and drives for industrial and alternate energy applications.

Dr. Pillay is a Fellow of the Institution of Engineering and Technology, U.K., and a Chartered Electrical Engineer. He is a member of the Academy of Science of South Africa, the IEEE Power Engineering, IEEE Industry Applications, IEEE Industrial Electronics, and IEEE Power Electronics Societies. He is also a member of the IEEE Industry Applications Society (IAS) Electric Machines Committee, the Past Chairman of the IEEE IAS Industrial Drives Committee, and the past Chairman of the IEEE Power Engineering Society Induction Machinery Subcommittee. He has organized and taught short courses on electric drives at the Annual Meeting of the IEEE Industry Applications Society. He is currently the Chair of the Awards Committee of the IEEE IAS Industrial Power Conversion Department. 